\title{
Accounting for the future: How will corporate business models deliver sustainability?
}

\author{
Colin HASLAM \\ Queen Mary University of London \\ c.haslam@qmul.ac.uk \\ Razvan HOINARU \\ Queen Mary University of London \\ r.hoinaru@qmul.ac.uk \\ Buda DANIEL \\ Babes -Bolyai University, Cluj- Napoca, Romania \\ daniel.buda@fspac.ro
}

\begin{abstract}
This paper considers the information value of carbon-emissions disclosures for investors. Our argument is that Financial Institutions (FIs) do need to map the carbon-financial intensity of corporate activities so as to provide investors with higher returns on capital relative to the carbon emissions attached to this capital. Our analysis maps out carbon-financial risks in the S\&P500 constituent companies that are domiciled in the US and capturing approximately $82 \%$ of the total U.S. equity market value. We examine the extent to which carbon-financial risk has already impacted on the allocation of capital (debt and equity) and market value exposure from carbon emissions in the S\&P500. Our analysis of carbon generating and carbon dependent business models in the S\&P 500 reveals a complex and interconnected physical-financial value chain. This new insight will force FIs to now become active investor's rather than simply investing (or disinvesting) at a distance in order to secure a long- term decarbonisation of their portfolios. This papers also argues for new innovative disclosures such as company's reporting their top 10 material carbon-stakeholder relations. This would help FIs understand a company's business model in terms of carbon interdependency and inform regulatory and technical interventions thereby avoiding the possibility of a disruptive evacuation of capital from carbon-intensive business models.
\end{abstract}

Keywords: Carbon emissions, carbon generating and carbon dependent business models, carbon-financial value chains

\section{Introduction}

After the Kyoto Protocol was signed in 1997 international climate conferences such as Montreal 2005, Copenhagen 2009 and Paris 2015 have consolidated a political commitment towards setting long-term goals for reducing Greenhouse Gas Emissions (GHG). Specifically, the objective has been to reduce GHG and their carbon equivalent to levels that will arrest the increase in global average temperatures to levels that are below $2^{\circ} \mathrm{C}$ above pre-industrial levels. At the Paris climate conference (COP21) in December 2015 Governments agreed:

a long-term goal of keeping the increase in global average temperature to well below $2^{\circ} \mathrm{C}$ above pre-industrial levels; to aim to limit the increase to $1.5^{\circ} \mathrm{C}$, since this would significantly reduce risks and the impacts of climate change; on the need for global emissions to peak as soon as possible, recognising that this will take longer for developing countries; to undertake rapid reductions thereafter in accordance with the best available science (European Commission, 2018). 
According to a carbon footprint briefing note issued by ShareAction and TruCost, 'global emissions would have to fall by about $60 \%$ by 2050 to limit the increase in average temperature to less than $2^{\circ} \mathrm{C}\left(3.6^{\circ} \mathrm{F}\right)$ above pre-industrial levels. Over the last 40 years, $\mathrm{CO} 2$ emissions have continually risen and only stalling following major economic crises.' (ShareAction and Trucost, 2015). Table 1 reveals that outcomes have been disappointing. Although carbon emissions intensity has fallen from 0.48 tons of carbon per $\$ 1000$ of global GDP in 1990 to 0.32 tons in 2016, it is that case that GDP has grown at a faster rate thereby increasing overall global emissions from 22 billion to 36 billion tons of carbon equivalent emissions annually.

The world's major industrial and industrialising economies have not found a way of decoupling carbon emissions from economic growth and carbon emission concentrations in the atmosphere have increased from 355 to over 400 parts per million.

Table 1: Global carbon emissions in relation to GDP and atmospheric concentrations
\begin{tabular}{|l|c|c|c|c|c|}
\hline & 1990 & 2000 & 2010 & 2016 \\
\hline Tons of carbon /1000\$ of GDP & 0.48 & 0.41 & 0.37 & 0.32 \\
\hline Total C02 emissions bill tons & 22.5 & 25.6 & 33.6 & 35.8 \\
\hline C02 parts per mill in atmosphere & 355.0 & 370.6 & 388.7 & 402.5 \\
\hline
\end{tabular}

Sources: For carbon emissions parts per million in atmosphere as at Jan $1^{\text {st }}$ of these years (Tans et al., 2018). For data on total global carbon emissions in relation to GDP (European Commission, 2017a)

Since the Kyoto Protocol was signed in 1997 the emphasis has been on installing a top down legalistic driven regulatory model with the necessary authority to establish a unified global political commitment to reducing carbon emissions. However, this approach has been progressively undermined as global carbon emissions continued to increase and political commitment is fractured. In recent years attention has changed towards promoting the contribution that financial markets and financial institutions (FIs) could make towards reducing carbon emissions. This FI driven approach to decarbonizing corporate business models has been advocated by the United Nations Environment Programme (UNEP) and European Commission (EC).

It is possible that new financial markets such as carbon cap and trade could limit the growth in carbon emissions. These markets have already been tried out in Europe and to some extent to US but with limited impact on carbon emissions. The alternative approach already noted, and the focus of this paper, is the contribution of financial institutions (FIs) to promoting portfolio decarbonisation. If we are to reduce carbon emissions FI's will need to direct capital allocations away from more to less carbon intensive business models. If it is perceived that there is an increasing risk attached to investing in carbon intensive activities, for example heightened exposed to regulatory and technical changes, that could lead to 'stranded assets' or a 'carbon bubble' (Carbon Tracker, 2018).

Whilst there has been a steady increase in our understanding of climate change from a scientific-environmental risk perspective, for example, the increase in volatile climatic events (Climate Change Institute). There is still the challenge of translating this understanding of risk into meaningful sustainable behaviour within corporations and financial institutions that allocate capital. Specifically, this would involve incentivising 
companies that are carbon intensive to move to a less carbon intensive trajectory. Connecting the science of climate risk arising from carbon emissions to changes in corporate behaviour is, as we have noted, not an easy task but recent policies have centred on encouraging new financial markets to trade in carbon off-set credits and of encouraging financial institutions (FIs) to change their asset allocation behaviour away from more to less carbon intensive investment portfolios.

With regards to financial market interventions designed to reduce carbon emissions the European Union Emissions Trading System (EUETS), the world's largest carbon cap and trade system, was launched in 2005 and the UK Government believed that: The EU Emissions Trading System (EU ETS), the world's largest cap and trade system, should remain the cornerstone of EU energy and climate change policy. The EU ETS demonstrates Europe's ambition to act as a global leader in the fight against climate change through the delivery of a functional and effective carbon market. The continued success of EU ETS is vital in helping the EU to meet its 2030 and 2050 targets at least cost, and in laying the foundations of a global carbon market (United Kingdom Government, 2014)

The EU ETS operates on the basis of what is termed a 'cap and trade' principle. Within the EU a target is set for the overall volume of greenhouse gases that can be emitted by energy power plants, industry and other sectors covered by a cap on carbon emissions set at EU level. Within this overall cap some companies may be under target and so obtain allowances which they can trade with other companies/sectors that are above their targets (European Commission, 2016)

However, the support for EU ETS is waning and this is summed up in a recent European Commission (2017) report which observes that there is a considerable gap between the shadow price for carbon emissions employed by the European Investment bank (EIB) of €32/tCO2 and so-called market price of less than €5 euro. This low 'price' for carbon emissions obscures the difference between assets that are carbon efficient and those which are not.

The absence of a financially material carbon price prevents investors from differentiating carbon-intensive assets from carbon-efficient assets in their economic reasoning. The EU emissions trading system (ETS) price of carbon for a DEC17 EUA is currently about $€ 5$. The EIB, by comparison, uses a shadow cost of carbon of $€ 32 / \mathrm{tCO} 2$ today, rising €1 each year to €45/ tCO2 in 2030 (European Commission, 2017: 42)

The promising alternative to a 'market' based cap and trade approach to reducing carbon emissions is that of encouraging Financial Institutions (FIs) to modify their investment behaviour, that is, allocate capital away from more to less carbon intensive portfolios. It is this approach to decarbonisation, and how it might be framed, that informs this subject of this working paper.

Specifically, it is argued that a change in investment strategy by FIs is required because carbon intensive investments present increased value at risk due to possible changes in regulation and threats from new technology. This might then lead on to FIs facing exposure from so-called 'stranded assets' or a 'carbon bubble' (UNEP, 2015, European Commission, 2017).

The carbon bubble poses risks to the financial sector because financial institutions have large exposures to oil, gas and coal mining companies through equity, bond, and loan portfolios (Weyzig et al., 2014)

Investors, we are informed, have been leading on the decarbonisation of their investment portfolios but, the combined exposure of their equity portfolio to carbonintensive sectors remains large [45-47\%] (European Commission, 2017). Others argue 
that carbon risk is not be modifying investor and analyst's behaviour in a way that progressively mitigates climate change risk (Campbell \& Slack, 2011; Harmes, 2011; Pattberg, 2012).

In the following section we turn to consider the information value of carbon emissions disclosures for investors. We then turn towards mapping carbon-financial risk in the S\&P 500 to review the extent to which different business models present lower carbon- financial risk. Then we ask to what extent can FIs modify their aggregate portfolio risk in a complex carbon-financial value chain? We finally turn to setting out a wish list in terms of what innovative non-financial disclosures FIs need to seek from financial reporting/disclosure standards and how this information might inform interventions within business model value chains where contradictory financial and physical relations are operating.

\section{Information value of carbon emissions disclosures}

Mark Carney, Governor of the Bank of England, observed in 2015 that: an old adage is that which is measured can be managed [and] information about the carbon intensity of investments allows investors to assess risks to companies' business models and to express their views in the market' (Carney, 2015:12).

In the same speech Mark Carney notes that the way in which carbon emissions are measured should be consistent - in scope and objective across the relevant industries and sectors (Carney, 2015).

There is also an additional challenge which is that measured and disclosed by companies about their carbon emissions will change over a period of time because, as Lohmann (2009) observes, there are considerable problems controlling the boundary of a company (see also Haslam et al, 2014). And, there are other problems associated with encouraging disclosures if these are voluntary rather than a regulatory obligation (de Aguiar \& Bebbington, 2014).

There are also considerable challenges and health warnings attached to translating carbon arising from different greenhouse gases into a company based measure (Andrew \& Cortese, 2011). In this paper our investigation of carbon-asset risk in the S\&P 500 constituent group of companies relies on information on carbon emissions collected by CDP, formerly known as the Carbon Disclosure Project. CDP supports companies in terms of technical advice on how to measure their GHG emissions and how to convert these into a C02 equivalent. CDP collects C02 equivalent data from companies and these are allocated into what are known as Scope 1, 2 and 3 emissions categories.

Scope 1 carbon emissions are from operations that are owned or controlled by the reporting company whilst scope 2 emissions are indirect emissions from the generation of purchased or acquired electricity, steam, heat or cooling consumed by the reporting company. Scope 3 emissions include upstream and downstream value chain emissions and are an optional reporting category in the Corporate Standard (WRI \& World Business Council for Sustainable Development, 2001).

In this paper we employ scope 1 and 2 carbon emissions disclosed by companies in the S\&P 500 that disclose carbon emissions and provide matching key financial operating data over the period from 2008 to 2014. Table 2 reveals the aggregate carbon emissions for this group of companies for the period 2008 to 2014 at roughly 2 billion tons. 
Table 2: Carbon emissions S\&P 3132008 to 2014

\begin{tabular}{|c|c|}
\hline & $\begin{array}{l}\text { missions } \\
\text { ons) }\end{array}$ \\
\hline 2008 & 2.055 \\
\hline 2009 & 2.056 \\
\hline 2010 & 2.072 \\
\hline 2011 & 2.126 \\
\hline 2012 & 2.074 \\
\hline 2013 & 2.095 \\
\hline 2014 & 2.039 \\
\hline
\end{tabular}

PICBE | 821

Source: CDP public datasets (https://data.cdp.net/browse) and also authors' own investigations.

In this paper we employ information from companies listed in the S\&P 500 constituent list because companies (reporting entities) are allocated to industry sectors rather than establishments. The S\&P 500 constituent list employs the S\&P500/MSCI Global Industry Classification Standard (GICS) and this assigns companies to a single GICS sub-industry 'according to the definition of its principal business activity as determined by Standard \& Poor's and MSCI. Revenues and earnings are a significant factor in defining principal business activity'(S\&P). A company is assigned a classification at each of the four levels of GICS; however, a company may only belong to one group at any level. The S\&P 500 industry classification is generally determined by the nature of the activities carried out by the company as represented by the majority of a company's revenues and/or earning that is the nature of its business model. The S\&P methodology for locating companies into an industry integrates into its methodology a market-oriented perspective which takes into account that both production and services are comingled within companies.

These reporting entities (companies) are, as we have noted disclose their scope 1 and 2 level carbon emissions. Our analysis of carbon emissions for the S\&P500 group identifies 313 out of 500 that survive and remain listed in the S\&P 500 constituent list and have also disclosed both their carbon data and matching financial data for this period.

In figure 1 we split the S\&P 313 group of companies into those that are carbon generators (energy utilities and energy supply) and those business models that are carbon dependent such as energy extractive, materials processing and then all 'other' business models. This we accept is not a clean process because materials processors and energy extractive business models may have their own power plants and energy supply. Our objective is to generate a broad conceptual framework within which to discriminate between business models that are consuming carbon to generate and supply energy and business models that are carbon dependent business models by virtue that they require energy as an input or semi-processed physical components and materials. 


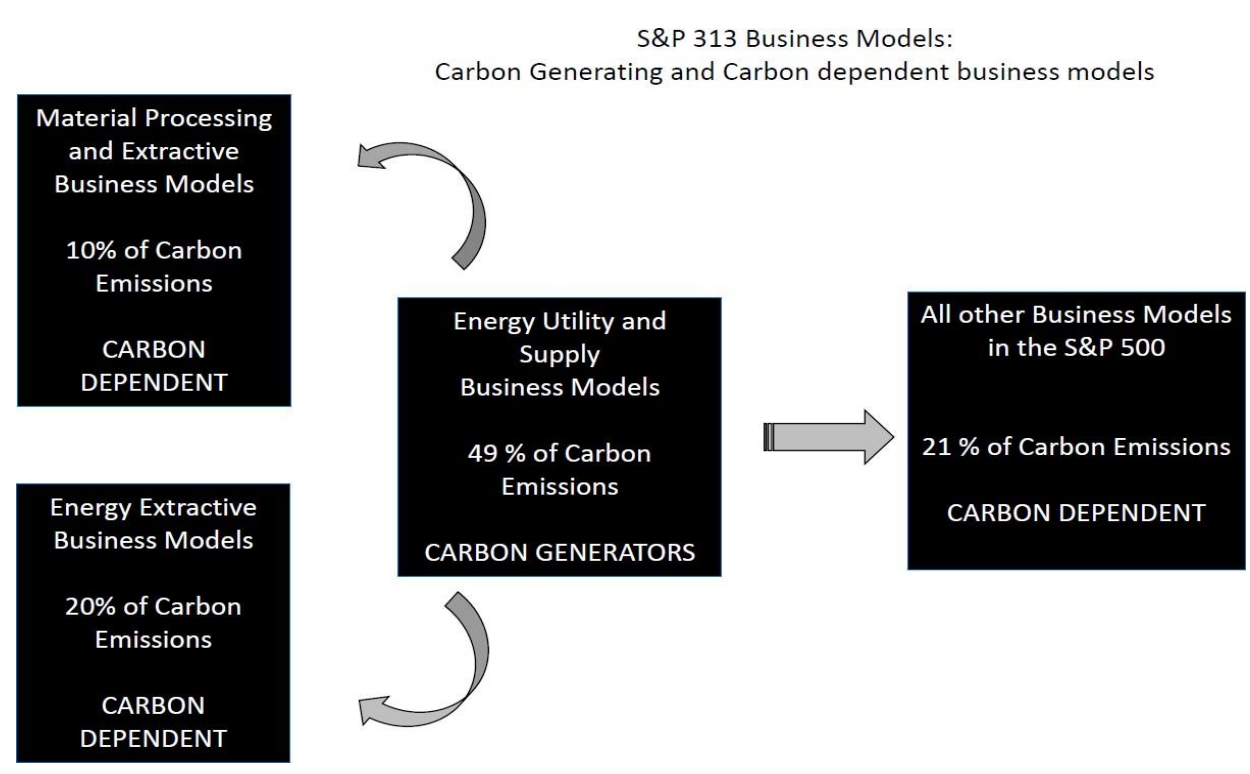

Figure 1. Carbon Generating and Carbon dependent business models

Source: Authors' own design.

Although this is not a clean scientific split it reveals that materials processing and energy extractive business models are dependent upon approximately 30 percent of the S\&P 313 carbon emissions and all other business models approximately 20 percent.

In figure 2 we now add the business model share of capital employed (debt and equity) and share of cash generated from operations (EBITDA) in the S\&P 313 group of companies. Once we add these key operating financials into the framework we find that carbon intensive business models (carbon generators) account for roughly percent of capital employed and cash generated in the S\&P 313 group even though 49 percent of carbon emissions. Our analysis reveals the carbon - financial operating characteristics of carbon generating and carbon dependent business models is complex and inter-related.

S\&P 313 Business Models: Carbon intensity and capital employed
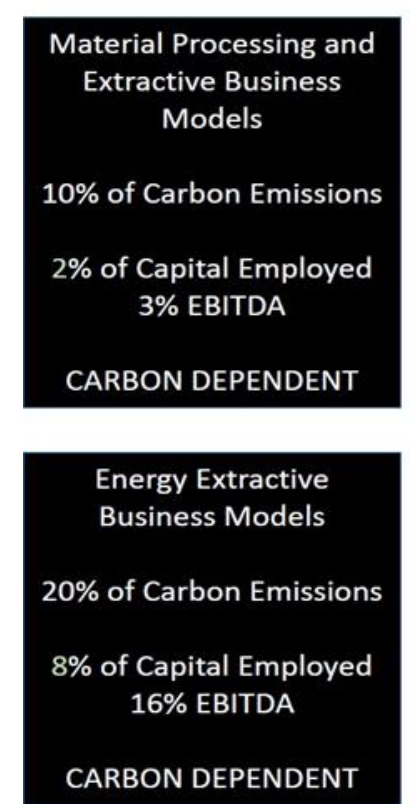
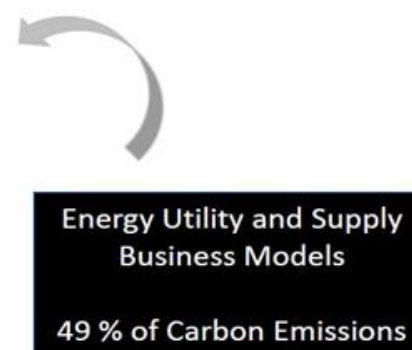

$6 \%$ of Capital Employed $6 \%$ of EBITDA

CARBON GENERATORS

\section{Figure 2. Carbon intensity and capital employed}

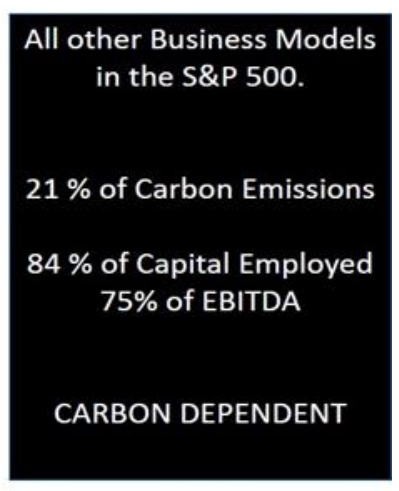

Source: Authors' own design. 
In terms of capital stack position (that is debt and equity funding) FI's have limited their financial exposure to carbon generating and or high carbon dependent business models. We find that the carbon intensive business models: energy utilities, materials processing and energy extractive account for approximately 80 percent of carbon emissions but account for just 16 percent of capital employed (debt and equity).

All other carbon dependent business models to the right in figure 2 account for roughly 20 percent of carbon emissions but 84 percent of capital employed. Our analysis is confirmed in table 3 which reveals a more contemporary picture of the S\&P 500 constituent's industry sector shares of carbon emissions and market capitalisation. Energy, materials and utilities accounting for 84 percent of carbon emissions but only 11 percent of market value. Which means that all other business models (carbon dependent) account for 16 percent of carbon emissions and approximately 90 percent of stock market value.

Table 3. S\&P 500 constituent's industry sector shares of carbon emissions and market capitalization

\begin{tabular}{|c|c|c|c|c|}
\hline GACS' SECTOR & $\begin{array}{l}\text { SUM OF EM SSIONS } \\
\text { DIRECT (KILOTONS CO20) }\end{array}$ & $\begin{array}{l}\text { NUMBER OF } \\
\text { COMPAMES }\end{array}$ & $\begin{array}{l}\text { CF TOTAL } \\
\text { DRECT } \\
\text { EMISSIONS }\end{array}$ & $\begin{array}{r}\text { \% OF INDEX TOTAL } \\
\text { MARKET } \\
\text { CAPITALI2ATON }\end{array}$ \\
\hline Energy & 350,757 & 32 & 19.7 & 59 \\
\hline Materials & 109,887 & 25 & 60 & 29 \\
\hline Industrials & 258,602 & 69 & 14.2 & 10.1 \\
\hline Consumer Discrebionary & 30,444 & 84 & 17 & 125 \\
\hline Consumer Staples & 50,271 & 34 & 28 & 90 \\
\hline Heath Care & 8,845 & 62 & 0.5 & 13.5 \\
\hline Financisls" & 84,079 & 67 & 4.6 & 152 \\
\hline Intormason Technology & 7,954 & 68 & 04 & 233 \\
\hline Telecommunications Services & 1,785 & 3 & 0.1 & 20 \\
\hline Utilites & 912,180 & 28 & 500 & 23 \\
\hline Real Estate & 1,675 & 33 & 0.1 & 23 \\
\hline TOTAL. & $1,824,478$ & 505 & 100.0 & 100.0 \\
\hline
\end{tabular}

Source: http://www.indexologyblog.com/2018/01/31/carbon-emissions-history-of-the-sp-500-and- itssectors/

From this analysis we conclude that the information value of carbon emissions intensity has already been factored into capital allocations and market value calculations made by financial institutions such as big investment banks. For example, corporate activities that offer financial leverage relative to their carbon emissions are business models in financial services, informational technology and healthcare. These business models are able to lever substantial financial value out of the carbon they depend upon to maintain their activities.

However, reframing the analysis in terms of a physical (carbon) / financial value chain provides an alternative insight into the way in which companies are not isolatable but are located in a 'value chain' that is both complex and interdependent.

\section{From portfolio management towards business models and interdependency}

The analysis we have presented in section 2 reveals that FIs have limited exposure to carbon generating business models in terms of capital employed, cash earnings and market value. The average portfolio would be located in carbon dependent business models which, by virtue of their operational and market characteristics, convert materials 
and energy inputs into high value creating and capturing products and services.

However, our analysis that maps the carbon-financial value chain in the S\&P 313 group of companies also reveals that FIs continue to provide capital to carbon generating business models. They have not evacuated their positions in the expectation of a carbon 'bubble' or 'stranded assets'.

This makes sense for FIs because it is imperative that a steady and reliable supply of energy and energy intensive processed raw materials are provided to downstream business models. The capital invested by FIs therefore spans a more complex interdependent physical and financial value chain. That is, downstream business models to the right in figure 2, whilst less carbon dependent are able capable of delivering financial leverage and market value added (MVA) for investors and pension funds. The argument is that carbon-light business models are mutually dependent upon carbon intensive generating business models.

A business model framework of analysis is a useful and innovative way of considering:

[a] how carbon-financial risk has changed over time and [b] how we might envision new forms of carbon-risk disclosures and metrics.

It is argued that a business model is a form of organizational design that connects the internal perspective of the firm to an external network of relations and this framing can be employed to articulate how the firm interacts with stakeholders in the process of resource stewardship to secure financial viability (Baden-Fuller and Mangematin, 2013; Teece 2010). A firm's business model has been described as an activity system that encompasses a network of relationships that secure the development of new innovative technologies to renew product and process to lock in buyers and sellers to secure revenues and earnings for the firm (Zott and Amit, 2010; Zott, Amitt and Massa, 2011). This understanding of a firm's business model, as an activity system, involves locating the firm within an interdependent organizational activity network centred on the firm and its constituent partners and customers and driven by the need to create and capture value (Zott and Amit, 2010).

In the S\&P 313 group of companies we can identify a digital lifestyle business model (DLBM) which includes companies classified to a variety of industrial sectors the provision of: hardware, software applications and internet facilitation services. They belong to a business model because they collectively facilitate the provision of digital services to households and businesses.

This broadly defined business model also contains a group of companies that had a market value of roughly $\$ 1$ trillion in 2006 . This market value was, at this time, roughly equivalent to the market value of the S\&P 500 energy utility business model (see chart 1 ). By the year 2016 the market value of companies contained in the DLBM had increased to $\$ 3.5$ trillion but the market value of companies in the energy business model remained at roughly 2006 levels of $\$ 1$ trillion. And, although the DLBM only accounts for an average and steady 2.6 percent of the S\&P 313 total carbon emissions over the period 2008 to 2016 its share of total S\&P 500 market value increased from 6 to 18 percent. 


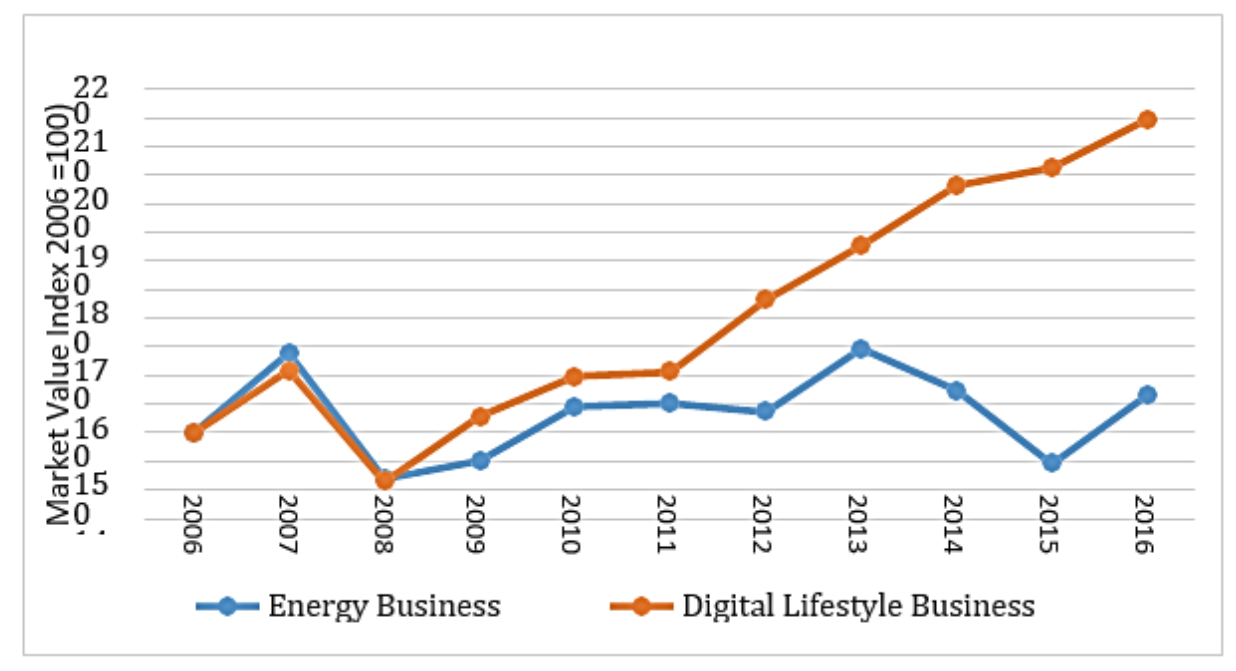

PICBE | 825

\section{Chart 1: US S\&P 500 Digital lifestyle and energy business models market value index Source: Authors' own design.}

The implications of our analysis are that downstream high value creating and capturing business models require inputs in the form of energy and materials that have been extracted and/or processed by business models that embody high levels of carbon emissions but represent a relatively low level of value at risk both in terms of capital employed and market value in the S\&P 313 group.

The physical-financial interdependency between upstream and downstream business models complicates matters. A disturbance to energy supply or raw material processing capacity could arise if FIs were to evacuate their capital positions in a disorderly way. If such a disorganised exit from carbon intensive upstream business models were to take place this would have ramifications for downstream business models which generate significant financial leverage from their relatively low physical carbon dependency. For example, a Carbon Tracker Initiative report in 2015 observes that:

Greater scrutiny is required for new projects, to take account of $89 \%$ of unneeded capex and $67 \%$ of avoided CO2. Over $\$ 2$ trillion of capex needs to not be approved in order to avoid around 156 GtCO2 of emissions - the equivalent of cutting supply and the subsequent emissions by around a quarter in the markets covered in this analysis.

This report emphasises the need to cut capex (capital expenditure) in carbon generating business models. This approach to carbon reduction avoids the challenges revealed in this paper concerning physical-financial resource interdependency between business models that are carbon generating and carbon dependent.

\section{Towards new business model disclosures for carbon reduction}

An alternative framing for carbon disclosures is one that reveals value chain interdependency between carbon generating and carbon dependent business models. These alternative disclosures could be framed around a company 'business model' which might best be described as a management technology that can be employed to reveal information about a company's broad stakeholder relations and how these are enhancing or degrading a reporting entities value proposition and sustainability. That is, to what extent are company stakeholder relations contributing to sustainability in terms of reducing carbon emissions generation and dependency whilst securing financial viability in terms of liquidity, solvency and market value added expected from a going concern 
(Haslam et al, 2015; Hoinaru et al, 2019).

This framing of a company as belonging to a business model focuses on how stakeholder interactions secure or put at risk the viability and sustainability of companies (financial reporting entities). Over a period of time these relations with stakeholders (financial, physical, environmental and regulatory) will change and may either promote the company's viability or undermine or compromise its value proposition (in the broadest sense).

The regulatory framework on carbon disclosures is currently focussed on getting companies to disclose their scope 1, 2 and 3 emissions based on their internal and external value chain. This is 'firm' centred and relies on a particular approach to accounting for carbon as an input in physical conversion. An alternative is a business model approach to accounting for carbon emissions. This alternative provides an account of a company/ reporting entity in terms of active engagement(s) between carbon generating and carbon dependent business models revealed as a series of carbon-stakeholder relations some of which are more 'carbon-material' than others.

We suggest that because the company/reporting entity is located within a network of stakeholder relationships that are more or less carbon intensive. Information about these networks would be important to investors. Moreover, 'material' disclosures are important here because it is necessary that reporting entities identify and disclose carbon-material stakeholder interactions. Thus companies might be asked to disclose their top 10 carbon-material stakeholders and provide a commentary on how and to what extent these relationships are being managed to decarbonise their business model (Haslam et al 2014).

This information would be of considerable value to FIs that are looking to engage in the process of decarbonizing value chains where a complex matrix of carbon generating stakeholder relations are in play. This information would convert FIs from passive to active participants in terms of modifying stakeholder relations towards a less carbon intensive future. This must include working with carbon 'generating' business models to ensure that the operational capacity if high value, less carbon 'dependent' business models are not compromised.

\section{Summary}

With regards to the information value of carbon emissions disclosures in the S\&P 500 group of business models we find that FIs have generally a low capital and market value exposure to carbon generating business models. Environmental risk in terms of the carbon intensity of business models has been factored into aggregate portfolio exposure in terms of capital and market value positions.

The corporate activities that provide investors with high financial leverage are those which belong to less carbon intensive but still carbon dependent business models that have a high propensity to generate financial leverage out of a relatively low level of carbon dependency.

Carbon risk will still impact on institutional portfolio choices because high value low carbon dependency business models whilst accounting for less than 16 percent of carbon emissions account for over 80 percent of capital employed and 90 percent of market value in the S\&P 500. This low level of carbon-risk dependency should not lead to complacency because intensive carbon generating business models operating upstream in the value chain provide inputs to downstream business models that convert these inputs into financial leverage. This interdependency in the value chain really matters and as yet corporate disclosures are not revealing this risk. 
Institutional investors need to start to ask for innovative disclosures that reveal how a company is nested within a network where some stakeholder relations are more or less carbon intensive. Revealing information about these dependency relationship(s) and what companies are trying to do to mitigate carbon risk will help to inform FIs as active investors trying to both decarbonise portfolios but also ensure that this is not a disorderly process that could put high value upstream carbon dependent business models at risk.

Complexity and interdependence between the generation of carbon emissions and dependency on carbon means that these two sides of the coin must be engaged simultaneously. There is a need drive down carbon emissions but we should be aware of the value at risk from relatively small changes in carbon dependency. This requires that companies be encouraged to strategically engage with stakeholders that impact materially on carbon dependency. It is therefore essential that sustainable resource policies are informed by innovative disclosures about how material-carbon stakeholder relations are being modified to take business models towards a mutually beneficial lower carbon future.

\section{References}

Andrew, J., \& Cortese, C. (2011). Accounting for climate change and the self- regulation of carbon disclosures. Accounting Forum, 35(3), 130-138.

Baden-Fuller, C \& Mangematin, V. (2013). Business models: A challenging agenda, Strategic Organization, (11): 418-427.

Campbell, D., \& Slack, R. (2011). Environmental disclosure and environmental risk: Sceptical attitudes of UK sell-side bank analysts. The British Accounting Review, 43(1), 54-64.

Carbon Tracker Initiative. (2015). The $\$ 2$ trillion stranded assets danger zone: How fossil fuel firms risk destroying investor returns https://www.carbontracker.org/reports/stranded-assets-danger-zone/.

Carney, M. (2015). Breaking the tragedy of the horizon - climate change and financial stability. Speech by Governor of the Bank of England and Chairman of the Financial Stability Board, at Lloyd's of London, London, 29 September.

de Aguiar, T. R. S., \& Bebbington, J. (2014). Disclosure on climate change: Analysing the UK ETS effects. Accounting Forum, 38(4), 227-240.

European Commission. The EU Emissions Trading System (EU ETS). (2016). https://ec.europa.eu/clima/sites/info/files/factsheet_ets_en.pdf.

European Commission. Financing a Sustainable European Economy. (2018)

https://ec.europa.eu/info/sites/info/files/180131-sustainable-finance-finalreport_en.pdf.

European Commission. (2017). Interim report - Financing a sustainable European economy. https://ec.europa.eu/info/sites/info/files/170713- sustainablefinance-report_en.pdf.

European Commission. (2018). Final report - Financing a sustainable European economy. https://ec.europa.eu/info/sites/info/files/180131- sustainable-finance-finalreport_en.pdf.

Harmes, A. (2011). The limit of carbon disclosure: Theorizing the business case for investor's environmentalism. Global Environmental Politics, 11(2), 98-119.

Haslam, C., Butlin, J., Anderson, T., Malamatenios, J., \& Lehman, G. (2014). Accounting for carbon and reframing disclosure: A business model approach. Accounting Forum, 38(3), 200-211. 
Haslam, C., Tsitsianis, N., Andersson.,T and Gleadle, P (2015) Journal of Business Models. (3:1): 62-80.

Hoinaru, R., Negreanu, A., de Luca, A., (2019). Driving Down Greenhouse Gases: A roadmap for the Paris Agreement. Printing Unit of the European Parliament.

IFRS Foundation. (2010).The conceptual framework for financial reporting. https://www.ifrs.org/-/media/project/conceptual-framework/fact-sheet-projectsummary-and-feedback-statement/conceptual-framework-project- summary.pdf.

Lohmann, L. (2009). Toward a different debate in environmental accounting: The cases of carbon and cost-benefit. Accounting, Organizations and Society, 34(3-4), 499534.

Pattberg, P. (2012). How climate change became a business risk: Analyzing non-state agency in global climate politics. Environment and Planning C: Government and Policy, 30(4), 613-626.

United Kingdom Government. EU Emissions Trading System - the future of the system. (2014). https://www.gov.uk/guidance/eu-emissions-trading- system-the-futureof-the-system.

UN Environment Programme (2015). Carbon Asset Risk: Discussion Framework. http://www.unepfi.org/fileadmin/documents/carbon_asset_risk.pdf.

UNEP. (2012) Carbon asset risk. http://www.unepfi.org/fileadmin/documents/carbon_asset_risk.pdf.

Teece, D. J. (2010). Business Models, Business Strategy, and Innovation. Long Range Planning 43: 172-94.

S\&P. Global Industry Classification Standard. http://etfs.cz/images/clanky/GICS.pdf.

Weyzig, F., Kuepper, B., van Gelder, J. W., \& van Tilburg, R. (2014). The Price of Doing Too Little Too Late: The impact of the carbon bubble on the EU financial system. http://reinhardbuetikofer.eu/wp- content/uploads/2014/03/GND-CarbonBubble-web1.pdf.

World Resources Institute \& World Business Council for Sustainable Development. (2001). The Greenhouse Gas Protocol: A Corporate Accounting and Reporting Standard. http://www.ghgprotocol.org/files/ghgp/public/ghg- protocol2001.pdf.

Zott, C. \& Amit, R. (2010). Business Model Design: An Activity System Perspective. Long Range Planning, 43, 216-226.

Zott, C., Amit, R. and Massa, M. (2011). The Business Model: Recent Developments and Future Research, Journal of Management 37: 1019-42. 